\title{
O ambiente informacional e suas tecnologias na construção dos sentidos e significados
}

\author{
Henriette Ferreira Gomes \\ Professora do Departamento de Documentação e \\ Informação do Instituto de Ciência da Informação da \\ Universidade Federal da Bahia. Coordenadora científica da \\ Biblioteca Virtual de Educação à Distância - Prossiga/ \\ UFBA. Mestranda do Programa de Pós-Graduação em \\ Educação da Faced/UFBA. \\ E-mail:henriete@ufba.br
}

\section{Resumo}

No processo de construção do conhecimento, os sujeitos interagem entre si, inseridos nos ambientes da cultura. Isso se dá com o auxílio das diversas tecnologias da comunicação e informação, que se tornam relevantes na produção e utilização das informações no contexto da educação formal. Com o apoio dos recursos tecnológicos, o homem recria seus espaços culturais, amplia o acervo de conhecimentos e suas formas de circulação, como também explora novas possibilidades de apreensão e ressignificação do mundo, transformando a aquisição do conhecimento em um processo dinâmico e complexo.

\section{Palavras-chave}

Informação - semiótica; Processamento de informações; Tecnologias da comunicação e informação; Construção dos sentidos e significados.

\section{The informational environment and its technologies in building up senses and meanings}

\begin{abstract}
In the process of building up knowledge, the subjects interact among themselves, being inserted in a cultural environment. That is achieved by the aid of several communication and information technologies, which become relevant in producing and making use of information within the context of formal education. With the support of technological devices, man recreates his cultural spaces and enlarges the amount of knowledge and its circulation forms. At the same time, he explores new possibilities of apprehension and reconstruction of meanings of the world, by transforming knowledge acquisition into a dynamic and complex process.
\end{abstract}

\section{Keywords}

Information - semiotic; Processing of information; Technologies of the communication and information; Building up senses and meanings.

Artigo aceito para publicação em 02/05/2000

\section{INTRODUÇÃO}

Ao abordar a construção dos sentidos e dos significados, deve-se necessariamente refletir a respeito do papel da linguagem e da comunicação nesse processo.

Por meio das linguagens são criados espaços de representação de nossa identidade, de nossas ações no contexto sócio-histórico onde estamos inseridos. Pela via dessa representação, é possível percebermos o mundo e a nós mesmos como sujeitos sociais.

Com a criação de signos, significados e a elaboração de conceitos, buscamos compreender e explicar a realidade na qual vivemos, mas também criamos nossos valores, desejos e fantasias, que constituem nossas subjetividades geradas por nossas experiências e expectativas. Conforme Teixeira (1995, p.41), "essa distinção entre o vivido e o imaginado nos 'define' como sujeitos produtores de palavras, sentidos e significados. Sujeitos do tempo, da cultura e da comunicação." O homem constantemente processa informações originadas de suas relações com o meio ambiente.

O mundo vivido pelo homem (lebenswelt) é aquele no qual são vividas suas relações cotidianas. $\mathrm{O}$ ambiente exterior produz impressões que funcionarão como links de acesso à decodificação de futuras informações que serão captadas do meio, constituindo então o mundo interior (innenwelt) do sujeito. Mas o cérebro humano não funciona como um simples receptáculo, por possuir uma capacidade de reflexão que permite ao homem fazer previsões, generalizações e construir suas interpretações particulares.

No exercício da reflexão, o homem gera o espaço da subjetividade por intermédio do qual capta e compreende o mundo. Desta forma, ele enquadra e captura seus objetos de análise e, a partir de sua própria perspectiva, realiza sua interpretação, construindo seu próprio conhecimento.

O ato de refletir só se realiza pela via da linguagem, mediante a manipulação dos signos. E, na ação reflexiva, o homem tem a possibilidade de processar as informações. Em um processo semiótico, o homem utiliza a informação para fazer generalizações e previsões. 


\section{Henriette Ferreira Gomes}

Desta forma, pode-se dizer que, no mundo vivido (lebenswelt), estão as coisas com suas propriedades, que não dependem da mente humana para existir. Mas, os nomes que se dão a elas são criações humanas, existentes apenas na mente do homem, e não na coisa em si. Nomear uma coisa significa realizar sua objetivação, que, conseqüentemente, gerará uma abstração e uma conceituação. O resultado dessa abstração representará o objeto que existirá no mundo interior (innenwelt). Assim, podemos dizer que a coisa pertence ao lebenswelt e o objeto ao innenwelt.

Nessa interação entre o "mundo interior" e o "mundo exterior", o signo é um intermediário entre as coisas existentes no lebenswelt e a sua objetivação na mente, no innenwelt. O objeto é a abstração da coisa, é a coisa significada a partir da manipulação do signo, isto é, o próprio significado. A partir da manipulação do signo (linguagem), gera-se na mente o signo interpretante em um processo de semiose, que é a formação do sentido.

Para Pinto (1996, p.89), "a semiose faz desta semiótica uma lógica ternária, isto é, uma forma de pensar que está assentada na noção de tríade, ou de relação triádica". A tríade ocorre a partir da mediação do sujeito, do objeto e de um signo do objeto, formando a figura 1.

Para Peirce (1989), a mediação é que determina a lógica ternária pela qual ocorre a compreensão do objeto por meio do seu signo. A compreensão se concretiza com base em três tipos de categorias de experiências: a primeiridade, a secundidade e a terceiridade.

A primeiridade (figura 2) é a experiência não reflexiva, que está muito próxima da singularidade da coisa. $\mathrm{Na}$ secundidade (figura 3), observa-se o objeto como um outro, quando se percebe a sensação, a qualidade do objeto tal como se forma em nossa mente (é a experiência do outro). Isso ocorre em uma relação binária em que o presente é definido pela experiência do passado. Nossas experiências anteriores são conectadas à experiência do momento presente. Tal reflexão se dá ainda em um nível de grande aproximação com o objeto. Mas é finalmente na terceiridade (figura 4) que se formará a significação (o sentido). Com o processo de abstração, surge um terceiro elemento que mediará a relação entre o sujeito e o objeto, tal elemento é denominado signo interpretante, o sentido.

Quando a semiótica tenta compreender a natureza do signo, da significação e da comunicação, estabelece um diálogo importante com as ciências cognitivas, trazendo uma contribuição relevante à educação.
FIGURA 1

\section{Relação triádica}

\section{OBJETO (significado)}

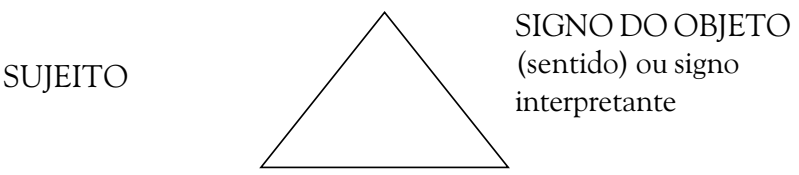

FIGURA 2

Representação da primeiridade

Primeiridade - experiência não reflexiva

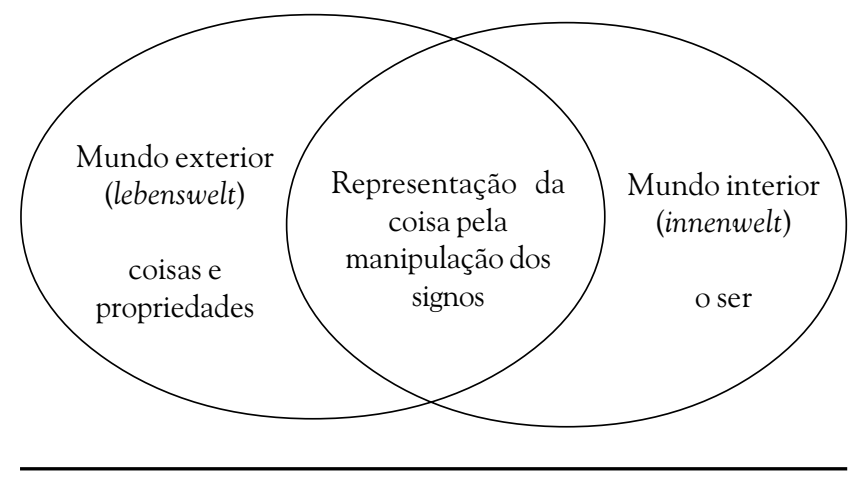

FIGURA 3

Representação da secundidade

Secundidade - manipulação dos signos e observação do objeto

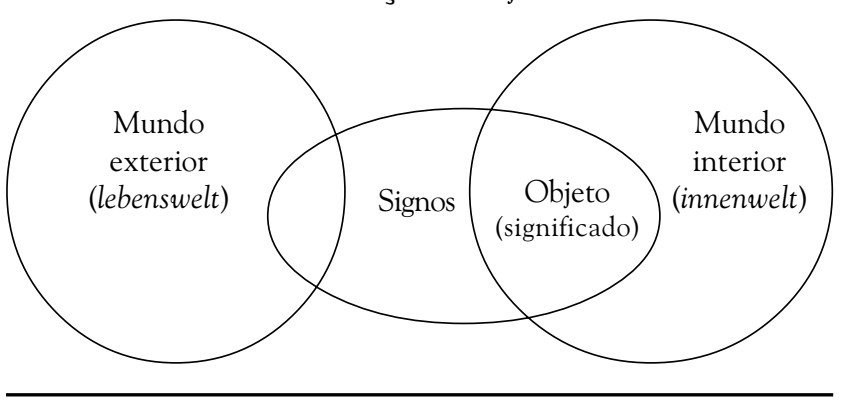

FIGURA 4

Representação da terceiridade

Terceiridade - compreensão e abstração do objeto

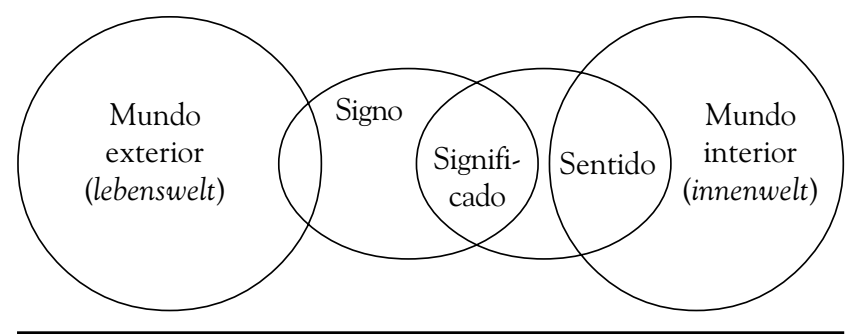


Sebeok (apud Nöth, 1998, p.125) "declarou que a semiótica é uma ciência cognitiva 'avant la lettre' e que as ciências cognitivas são, em si mesmas, variantes da semiótica."

Quando Pierce constrói sua tríade da primeiridade, secundidade e terceiridade, aponta momentos importantes da construção do conhecimento, indicando que este resulta de um processo de interpenetração do sentimento, da volição e da própria cognição.

A percepção imediata (primeiridade) está ligada ao sentimento, não possibilitando, portanto, o estabelecimento de diferenciações. Mas a volição mobiliza a ação interativa que inaugura o processo de diferenciação (secundidade), que se intensifica na comunicação, gerando a construção de nossas representações do mundo (terceiridade), que correspondem aos nossos conhecimentos adquiridos.

Assim, a construção dos conhecimentos, que é objeto da educação, representa um elemento da tríade concebida por Peirce enquanto processo de significação.

A cognição só é possível por intermédio dos signos e pode ser considerada como um processo de interpretação, de compreensão através da construção de modelos mentais, indicando a natureza semiótica destes processos e também o importante papel da mediação na construção do conhecimento.

Os sujeitos ligados ao ensino-aprendizagem estabelecem entre si um processo de interação, que também envolve suas práticas comunicativas realizadas com o apoio dos diversos recursos tecnológicos. Nesse processo, constroem seus modelos mentais que permitem a mediação entre o "mundo interior" e o "mundo exterior", possibilitando assim a construção de seus conhecimentos.

Embora os sujeitos sociais não resultem apenas da interação que se estabelece na escola, será no interior desta que seus conhecimentos terão a possibilidade de uma elaboração mais sistematizada. Sendo assim, a escola deve desenvolver suas práticas, levando em consideração toda complexidade dos movimentos que geram a significação, propiciando as condições necessárias à construção do espírito científico, ao desenvolvimento de uma cultura científica, na qual o conhecimento seja considerado enquanto um "conhecimento possível", que sempre é adquirido a partir de um processo dinâmico, abandonando, portanto, seu caráter estático (Gomes, 1999).
Desta forma, à luz da semiótica, a educação poderá melhor compreender os processos de mediação que interferem na construção dos conhecimentos, formulando estratégias pedagógicas que valorizem o papel da interação e dos processos de comunicação realizados com o auxílio das diversas tecnologias que viabilizam as práticas educacionais.

Ao realizar a educação nessa perspectiva, a escola poderá interagir de forma mais produtiva com outros ambientes produtores e transmissores de informação, compreendendo a si mesma como constituinte do ambiente informacional, que envolve outros espaços da sociedade, como bibliotecas, museus, serviços de informação, meios de comunicação de massa entre outros "espaços culturais" que também interagem com os sujeitos no processo de construção dos sentidos.

Por outro lado, também é importante ter claro o locus do ambiente informacional no processo de significação, não desconsiderando o espaço das subjetividades que interagem na aquisição do conhecimento.

No ambiente informacional (figura 5), em um primeiro momento, temos a informação, isto é, as coisas significadas a partir das quais, por intermédio dos signos, será iniciada a compreensão do objeto. Em um segundo momento, iniciamos o aprofundamento do nosso contato com o objeto, por meio do qual nos apercebemos dessa informação e iniciamos o processo de reflexão que nos levará à abstração, à construção do sentido. Esse movimento é constante, dinâmico e complexo, revelando, ao mesmo tempo, a não-linearidade e as inúmeras possibilidades do processo de aprendizagem.

\section{FIGURA 5}

\section{Representação do ambiente informacional}

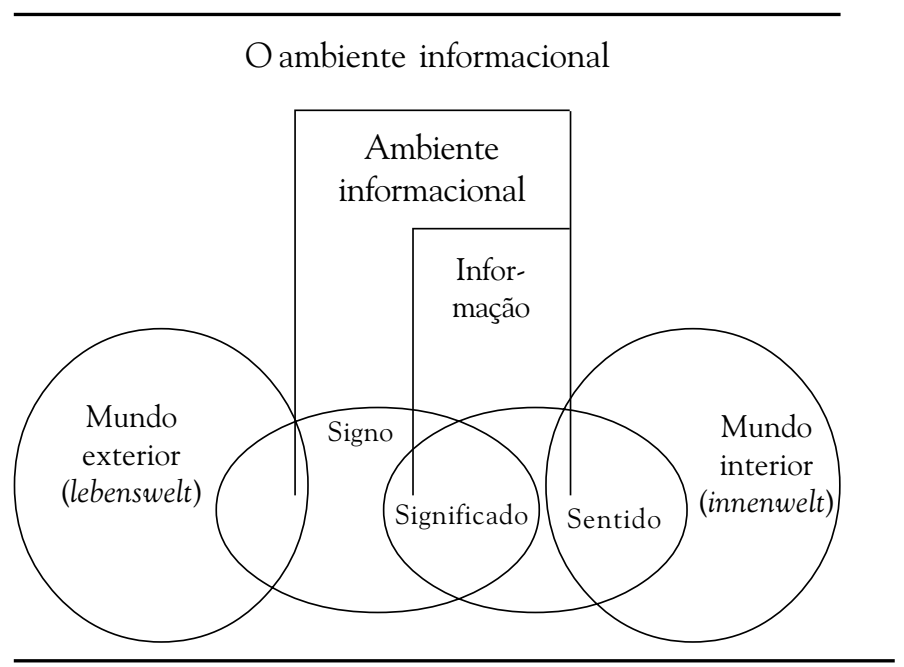




\section{Henriette Ferreira Gomes}

\section{A PRODUÇÃO E O USO DA INFORMAÇÃO: NO UNIVERSO DA FORMAÇÃO DOS SENTIDOS E SIGNIFICADOS}

Considerando que o sujeito está inserido em um tempo e em um espaço determinado, verificaremos que ele é agente de uma determinada cultura, na qual produz suas falas, constrói seus valores e os seus sentidos por meio da linguagem, mas não realiza nenhuma destas produções como um agente isolado. Na verdade, esta é uma construção coletiva, fruto da interlocução com os diversos "textos" cujas leituras já tenha feito anteriormente. "O que diz tem a ver com o que já ouviu dizer, com o que vão dizer, com o que pode dizer, com o que quer dizer" (Teixeira, 1995, p.42).

Como resultado das experiências vividas e das práticas comunicativas, construímos um acervo informacional composto de dois ambientes: o individual e o público. $\mathrm{O}$ ambiente individual relaciona-se ao "acervo armazenado" na memória, no qual residem nossas lembranças, experiências, valores, comportamentos etc., enfim correspondem à subjetividade. $\mathrm{O}$ ambiente público relaciona-se aos acervos compostos dos conhecimentos comunicados, materializados em um "artefato" que chamamos informação, correspondendo ao ambiente da objetividade.

No ambiente informacional público, o conhecimento encontra-se materializado mediante uma determinada linguagem, em um determinado suporte, o que assegura sua navegação para além do espaço e do tempo de sua construção. Isso faz com que ocorra um distanciamento do contexto da narração e do calor da enunciação.

Assim, a informação pode ser acessada e utilizada em um contexto diferente daquele em que foi produzida, podendo, portanto, ser recontextualizada. Esta é uma particularidade da informação, a de poder ser utilizada fora do seu contexto de criação. Fernandes apud Pacheco (1995, p.21) coloca que “... informação é aquilo que liga coisas que por algum motivo estão separadas. Assim, a informação implicará sempre recontextualização, porque sua dimensão espacial é extremamente dinâmica."

Por outro lado, a distância que pode estar estabelecida em termos de espaço e tempo entre o emissor e seus receptores pode representar um obstáculo à compreensão, erguido a partir de uma série de fatores culturais. É neste sentido que a ciência busca um padrão universal para a transferência de suas informações.
Com a modernidade, o conhecimento científico foi fragmentado, surgindo então mecanismos para religar os diversos fragmentos, como os espaços institucionais para a gestão dos saberes, cuja função é a de administrar, para a sociedade, o conjunto dos conhecimentos estabelecidos, criando formas de controle e difusão desses saberes.

Entretanto, sendo impraticável exercer o controle sobre tudo o que se pode conhecer, realizam-se a seleção, a sumarização e a reordenação dos conhecimentos a fim de que estes possam ser colocados à disposição da sociedade. Tal processo pode representar a exclusão de saberes e de certos enfoques, mas representa também um espaço de interlocução, no momento do acesso ao conhecimento, com vários sujeitos, e não somente com seus emissores originais.

O saber não ocorre mecanicamente, ele é elaborado a partir do estabelecimento de prioridades em termos do que deve e/ou se deseja conhecer. Além disso, a partir do acesso para processamento das informações, é necessário um distanciamento para que se dê a construção do conhecimento, ressaltando-se que tal movimento exige um processo de comunicação, que não se estabelece apenas entre um pólo emissor e outro receptor, mas também por canais de transferência de informação que interagem como mediadores da ação comunicativa.

Quando a informação (conhecimento comunicado) chega ao receptor, também não será absorvida automaticamente pelo mesmo. Este tem suas competências, um saber acumulado, experiências vividas, que dialogarão com o texto recebido, mediando a interpretação e compreensão. Isso representa uma cadeia de enquadramentos que interferem na construção do conhecimento, na qual a interpretação é uma ação de composição e, ao mesmo tempo, de exclusão de conexões que ocorrem em função do momento e do espaço em que se encontra o sujeito que interpreta.

A interpretação exige uma distância e um espaço para a atribuição do sentido, que resulta das conexões entre as dimensões intra e interpessoais. Como resultado, chegase à formação do conhecimento, que poderá então ser representado e comunicado, gerando uma nova informação. Mas, segundo Mari (1996, p.94), essa "ação interativa" ainda não é uma ação da interlocução necessária à comunicação de um conhecimento. Desta forma, o conhecimento é gerado nas "ações interativas", mas pode ser comunicado apenas por meio de ações de interlocução. 
No processo de interlocução, o sujeito realiza um esforço para viabilizar o compartilhamento do seu conhecimento com outros sujeitos. E, a depender da tecnologia utilizada no momento da enunciação da informação, o outro poderá ser virtual e encontrar-se, portanto, apenas temporariamente, em uma posição de passividade, na qual a possibilidade da existência da "contrapalavra" pode ser considerada como utopia, marcando o sujeito da comunicação pela impressão de isolamento e de domínio completo da ação comunicativa.

Entretanto, mesmo as tecnologias que possibilitam uma fixação maior do registro e que excluem a necessidade do contato direto entre emissores e receptores não tornam impossível a concretização dessa "contrapalavra". $\mathrm{Na}$ recepção, sempre ocorrem a interpretação e a ressignificação, embora as diversas tecnologias da comunicação e informação, a depender de sua natureza e contexto de utilização, interfiram com maior ou menor intensidade na visibilidade e ampliação do espaço da "contrapalavra" ou do comentário.

\section{A mediação da escrita e das "novas tecnologias"}

A cultura escrita transformou profundamente o homem, sua consciência e memória. Com a escrita, surge a possibilidade de separar do texto a sua interpretação, fazendo com que esta última se torne mais visível. As palavras tornaram-se mais públicas e puderam ultrapassar as barreiras do espaço e do tempo.

A tecnologia da escrita foi um importante instrumento na geração de um novo estilo de pensamento, em que a oralidade passou a ser secundária e complementar à compreensão da palavra escrita, representando um novo ambiente na formação dos sentidos.

Com a palavra escrita, as idéias puderam ser fixadas, surgindo então condições mais adequadas às interpretações e reflexões. Ocorreu uma facilitação do desmembramento e manuseio da informação durante o processo de construção das abstrações, representando grande contribuição à elaboração do pensamento. A escrita possibilitou a intensificação de uma dialogia entre diversos textos, que enriqueceu as conexões intra e intersubjetivas, gerando maior interlocução.

Deve-se ressaltar que o pensamento descontextualizado* não é um produto da escrita. Entretanto, foi fortalecido

\footnotetext{
Pensamento que se estrutura com base na descontextualização, que é a capacidade de manuseio da informação em um processo de desmembramento da mesma.
}

por ela, especialmente a partir do processo de industrialização, que passou a empregar classificações e hierarquizações.

Através da escrita, o pensamento por descontextualização foi reforçado e interiorizado pela sociedade, cujo crescimento exigia intensamente um pensamento desse tipo. Pequenas sociedades transferem informações face a face entre pessoas em número limitado, em um ambiente de intimidade. Porém, com o crescimento da sociedade, que passou a envolver milhares de pessoas, a interação face a face diminui, crescendo por outro lado o contato com estranhos. Isso passa a exigir maior cautela na geração de informações. Enquanto em uma pequena sociedade a comunicação pode ser mais contextualizada, em função de que seus emissores e receptores compartilham o mesmo ambiente, tornando possível os movimentos de réplicas e tréplicas no tempo real da comunicação, em uma sociedade maior e mais complexa as circunstâncias ambientais e temporais variam entre os diversos agentes da comunicação, gerando a necessidade de um pensamento mais descontextualizado no processo de reflexão e construção das informações, a fim de eliminar possíveis barreiras que limitem a compreensão do que se deseja transmitir.

O conhecimento surge a partir da relação entre a fala e a situação, entre o texto e o contexto. Tal relação sofrerá as implicações dos limites dos canais de comunicação, que variarão conforme as transformações culturais. As relações da fala com a situação são reconstruídas de acordo com as mudanças que ocorrem no meio ambiente, envolvendo o próprio ambiente da comunicação. Cada mudança, conseqüentemente, repercutirá nas formas de representação, distanciamento, reflexão e cognição.

Com a tecnologia da escrita, o texto passa a ser um espaço de registro do objeto com limites claros, que, embora possa representar um ambiente de certa constrição, simultaneamente é um espaço aberto de construção dos sentidos. Apesar de tentar representar os sentidos construídos por seus autores, constitui-se em um canal de acesso a inúmeros discursos produzidos anteriormente, por diversas culturas, espaços territoriais e temporais, possibilitando assim um ambiente de intensa interlocução e dialogia. Entretanto, surge também o problema da dispersão nos processos de significação e de construção dos sentidos.

Enquanto a escrita preserva a informação fixada pelo texto, o sentido será reconstruído pelo sujeito leitor por meio de sua interpretação, sem a intervenção direta e imediata do emissor da mensagem. 


\section{Henriette Ferreira Gomes}

Na comunicação oral, o sentido e o significado encontramse mais fortemente mixados, em função do contato mais estreito com o momento da enunciação. A escrita permitiu ao homem separá-los, compará-los e analisá-los, em um momento diferente daquele da enunciação, com a possibilidade de retomá-lo a cada instante que a análise exigir, possibilitando um ambiente de interlocução mais crítico e dinâmico. A distinção do que é dado pelo texto e das suas diversas interpretações foi amplamente aplicada nas leituras realizadas pelo mundo científico.

A tecnologia da escrita passou a desempenhar o papel de extensão da memória de trabalho biológica, assumindo uma posição de auxiliar cognitivo do processo controlado de aquisição da memória, que mobiliza a atenção consciente e possibilita o uso de poucos recursos do sistema cognitivo.

As diversas tecnologias desenvolvidas pelo homem, da língua ao livro impresso e deste aos meios magnéticos, foram ampliando o volume de informações armazenadas fora do contexto da emissão, além de ampliar as possibilidades de acesso aos conhecimentos. Tal desenvolvimento criou condições de fixação das informações em um espaço exterior ao da memória biológica do homem, com um distanciamento maior da realidade imediata da enunciação permeada por emoções. Isso ampliou a capacidade de descontextualizar, de classificar as informações e conseqüentemente a possibilidade de um exame mais dialético das idéias.

A escrita inaugurou esse processo revolucionário do pensar humano, no qual a memória passou a estar separada do homem e da sociedade, mantendo o conhecimento estocado em um ambiente externo. Por outro lado, a criação da escrita favoreceu a separação do conhecimento de sua identidade pessoal ou coletiva. E, especialmente a partir da impressão, inaugura-se um período de "tábulas rasas" a partir do qual, em todos os planos da organização social, os homens passam a ter a pretensão de começar sempre do zero (Eisenstein apud Lévy, 1993).

Entretanto, a escrita trouxe também aspectos inovadores e fundamentais para a realização do pensamento abstrato. Com o registro correto das idéias e a sua difusão em larga escala, gerou um processo de acumulação e explosão do conhecimento.

Com o surgimento da informática, os ambientes e as condições de comunicação, processamento, armazenamento e recuperação das informações sofrem impactos em proporções novamente revolucionárias.
O suporte da informação passou a ser mais leve, móvel, maleável, podendo fixar, além da palavra escrita, a imagem e o som, realizando inclusive animação, decomposição, recomposição, indexação, ordenação, comentários e associações a diversos documentos que compõem o universo hipertextual.

Quando a comunicação do conhecimento se dava no campo da oralidade primária, a coletividade humana era uma só com sua memória. Depois, com a escrita, ocorreu, como disse Lévy (1993), uma "semi-objetivação da lembrança" e foi possível separar o conhecimento da identidade das pessoas, fazendo surgir uma preocupação com as verdades subjacentes.

A partir da informática, a memória foi objetivada, ganhando a operacionalidade e a velocidade de registro e acesso à informação importância maior do que a própria preocupação com a verdade, que passou a ser mais claramente compreendida enquanto uma verdade possível, admitindo-se sua provisoriedade.

As condições de obtenção de uma "verdade crítica", que se tornou mais intensa com a escrita, vêm se transformando. As teorias, com suas "verdades", tornamse cada vez menos definitivas em função da velocidade com que se processam as inovações/invenções.

Tanto a informática quanto a escrita estendem a memória de curto prazo do homem, sendo que a primeira atua como um elemento externo capaz de suplementar a capacidade humana de imaginar, essencial à simulação para uma análise antecipada das conseqüências de seus atos, função extremamente importante ao desenvolvimento do aprendizado.

Naturalmente o homem constrói modelos mentais sobre o que raciocina, para explorar as diversas possibilidades com as quais poderá se defrontar. Assim, as tecnologias da comunicação e informação, que Lévy (1994) preferiu chamar de "tecnologias da inteligência", pelo papel que desempenham de auxiliares cognitivos, oferecem grande possibilidade de ajuda ao desenvolvimento do raciocínio. Com as "novas tecnologias" surgem outras possibilidades de uma potenciação ainda maior de nossa capacidade criativa. Porém, o homem continua e possivelmente continuará utilizando os recursos da oralidade e da escrita, articulados aos da informática, já que tais recursos não representam etapas estanques de sua existência. As técnicas se articulam em intensidades variáveis, de acordo com o momento e circunstâncias da geração do conhecimento. 
As mudanças nas ecologias cognitivas promovem a expansão das formas de construção de conhecimento, podendo fortalecer ou enfraquecer algumas dessas formas, a depender do contexto. Porém, todas coexistem no cotidiano do homem, podendo ser conectadas nos processos intra e intersubjetivos, interferindo no grau de interlocução e na construção dos sentidos.

O pensamento é fruto de uma rede composta por elementos internos e externos ao homem, o que envolve seu "mundo interior" (biológico/mental), marcado por suas experiências e seu "mundo exterior" (meio ambiente). Nesta rede, não só as tecnologias, mas também as organizações sociais, a exemplo das escolas, das universidades e de outras agencias da sociedade, interagem e se conectam no processo dialógico, interferindo nas representações que são fundamentais na aquisição do conhecimento, que tem como atividades essenciais a comparação, a analogia e a argumentação.

O sistema cognitivo do homem tem uma arquitetura em que seus módulos especializados organizam as suas percepções, memórias e raciocínios de forma restritiva. A estes módulos, o homem articula dispositivos de representação e de processamento das informações, como a leitura, que ligam solidamente esses módulos às suas tecnologias intelectuais.

As competências mentais do homem estão divididas no mínimo em visual, musical, lingüística, lógicomatemática, espacial, corporal/cinestésica, interpessoal e intrapessoal, sendo que tais áreas da mente atuam sem uma supervisão e/ou controle sobre si mesmas. Mas o pensamento só pode ser formado a partir da articulação de diversos mecanismos, bem como através de operações heterogêneas e muitas vezes conflituosas dessas faculdades da mente, sendo o pensamento, portanto, resultado da ação interacionista entre o organismo, o meio ambiente e o funcionamento do sistema cognitivo.

Além disso, o pensamento se renova permanentemente em função dessa mesma ação interacionista, pois um conhecimento construído normalmente é retomado nas práticas comunicativas. A cada retomada, surge nova possibilidade de ressignificação, que muitas vezes se dá já a partir da própria comunicação desse conhecimento (informação).

Ao criar o artefato informação, o homem tenta enquadrar seu conhecimento, produzindo uma ordem que possibilite a sua comunicação, a interlocução. $O$ contexto em que realiza esse ato representa o momento da enunciação, que estará aprisionada pelo simbólico, ou pelo esforço realizado para a comunicação, ocorrendo assim um esfriamento da relação com a contenção dos afetos e emoções, ficando a enunciação secundarizada, tornando possível a visibilidade da informação em sua constituição lógica. Desta forma, as lacunas percebidas podem ser mais trabalhadas, levando ao processo de ressignificação.

Por outro lado, a enunciação de um conteúdo informacional, a depender das tecnologias utilizadas, poderá se realizar de diversas formas, repercutindo também no acesso aos significados e na formação dos sentidos.

\section{A TRANSFERÊNCIA DA INFORMAÇÃO E A CONSTRUÇÃO DO CONHECIMENTO NA EDUCAÇÃO FORMAL}

As informações são produzidas pela sociedade em suas áreas científicas e eruditas, bem como pela indústria cultural, na qual se encontram os agentes produtores e receptores das mesmas. Estes últimos necessitam de alguma bagagem prévia de conhecimentos para acessá-las, o que exige um nivelamento em termos desses conhecimentos entre os diversos sujeitos, que se dará mediante a educação formal. Ao tentar executar esse nivelamento, a escola, em todos os seus níveis, acaba também desempenhando o papel de agente produtor de informações, já que, ao realizar a seleção das informações que serão trabalhadas, acaba promovendo o seu reempacotamento. Essa seleção e reempacotamento implicam a exclusão de determinados sentidos, além da reordenação daqueles que serão comunicados.

Os saberes selecionados constituirão os programas disciplinares que tecerão as grades curriculares, chegando aos sujeitos no interior da escola como saberes dados, sem uma história. O espaço escolar institucional é formado por uma hierarquização de papéis que determinam que o professor tem a função de mediador do acesso pelos alunos ao conjunto de saberes selecionados. Todavia, existe uma margem de flexibilização que permite algum espaço para a criatividade, inovações e invenções, a fim de que não sejam comprometidas as bases que legitimam o processo pedagógico (Marteleto, 1995a, p.13-14).

$\mathrm{Na}$ mediação realizada pelo professor em sua prática pedagógica, busca-se facilitar a conexão dos conhecimentos fragmentados a fim de possibilitar a formação de um sentido de mundo pelos alunos. As informações selecionadas pela escola para dar o acesso a esses conhecimentos são aquelas que comunicam 


\section{Henriette Ferreira Gomes}

conteúdos valorizados socialmente, sendo, portanto, no ambiente escolar que se dá a interiorização pelos sujeitos dos paradigmas vigentes. Mas, tal interiorização não significa uma absorção integral, pois os sentidos se constroem de forma dinâmica a partir de um processo de interação entre o meio e cada sujeito, que carrega, no seu mundo interior, impressões deixadas por suas próprias experiências.

A educação realiza a reformatação do conhecimento produzido e que se mantém vigente em uma linguagem pedagógica, visando à disseminação dos conteúdos valorizados que compõem o leque dos saberes consolidados. Por outro lado, não se pode deixar de considerar o papel que a indústria cultural desempenha na produção dos sentidos, que, de alguma forma, dialoga com os sujeitos sobre tais saberes, quando tenta popularizálos com a atuação de suas agências de comunicação de informações.

Embora a indústria cultural não seja uma agência voltada à construção do conhecimento científico e ao desenvolvimento da cultura erudita, ocupa um espaço significativo de produção da informação, no qual uma parcela importante dos textos será experimentada pelos sujeitos. Isso significa que, nos diálogos que serão travados no processo de abstração, tais textos poderão se apresentar e contribuir com a construção dos sentidos.

Segundo Bakhtin apud Wertsch \& Smolka (1994, p.127),

"Na 'dialogia fundante' as vozes entram em contato no tipo de interação face a face alternada, geralmente associada à idéia de diálogo. [...] Uma das maneiras pela qual a dialogia fundante se manifesta é no processo de 'compreensão' ... “.

Assim, entendendo que as impressões que cada sujeito carrega em seu interior são causadas pelo todo de suas experiências, que envolverão também aquelas proporcionadas pelo contato com as informações geradas pela indústria cultural, deve-se compreendê-las enquanto produtoras de informações que também são utilizadas na base da formação dos sentidos.

Na busca de um espaço dialógico, a educação, ao reenfocar as informações, deve também considerar as experiências socioculturais vividas pelos alunos fora do ambiente escolar. Isso implica então um espaço de recontextualização.

O primeiro momento de recontextualização é aquele no qual o professor promove a seleção dos conteúdos, organiza os currículos, carga horária, bem como quando, por meio de métodos predeterminados, classifica e reorganiza os conteúdos retirados dos acervos informacionais, nos quais estão registrados os diversos discursos teóricos socialmente aceitos, colocando-os em termos apropriados à prática pedagógica. Nesse primeiro momento, ele também estabelece as formas de comunicação que utilizará no processo de transferência das informações.

De outra maneira, o segundo momento é aquele no qual os alunos, em uma ação interativa, irão recontextualizar tais informações de acordo com suas próprias experiências. O processo de recepção de cada sujeito significa uma interpretação própria, um novo espaço de construção dos sentidos, onde a sala de aula é apenas um dos ambientes pedagógicos da escola onde se inicia essa construção, já que há espaços como a biblioteca, os laboratórios e as atividades extraclasse, que, em conjunto com o universo intra-subjetivo de cada sujeito, intermediarão a formação dos sentidos (Marteleto, op. cit.).

\section{A seleção da informação e a dispersão na formação dos sentidos}

Quando se verifica que a indicação dos conhecimentos que devem ser transmitidos é realizada por determinadas agências da sociedade, a exemplo da escola, constata-se que há, no fluxo das informações, uma tentativa de controle sobre a construção dos sentidos. Entretanto, tal construção se dá em um processo dinâmico, envolvendo as realidades socioculturais de cada sujeito e seus processos inter e intra-subjetivos, que acabam por criar espaços de flexibilização que impedem um controle absoluto sobre os sentidos.

Desta forma, um outro aspecto importante que deve ser considerado nas práticas pedagógicas é a dispersão das informações previamente selecionadas. As informações transmitidas por meio dessas práticas não serão completamente absorvidas, pois haverá um confronto entre estas e aquelas anteriormente interiorizadas pelos alunos. Inevitavelmente ocorrerá uma dialogia de diversas enunciações, tanto do universo intra-subjetivo, quanto do intersubjetivo, a partir da qual cada sujeito estará construindo a sua própria compreensão, podendo então gerar nova informação.

Pode-se assim concluir que a compreensão e mesmo os próprios processos de transferência da informação sempre serão incompletos. Nenhum conteúdo poderá ser plenamente dissociado de seus contextos de geração e de interpretação, que carregam os sentidos de impressões singulares. 
Neste sentido, as práticas pedagógicas devem se desenvolver de forma a garantir que os sujeitos possam ter acesso aos diversos referenciais, às diversas teses, sobre os objetos estudados (multirreferencialidade) e ao mesmo tempo possam ter a possibilidade de, a partir do contato com as diversas dimensões destes objetos (multidimensionalidade), construir progressivamente o conhecimento (Burnham, 1993, p. 7-8).

As tecnologias da comunicação e informação encurtam o circuito de acesso às informações, fazendo com que se torne invisível a cadeia de intermediários que interferiram na sua construção. Desta forma, quem toma contato com a informação tem a tendência a compreendê-la como autônoma e impessoal. Isso pode limitar a reflexão crítica e reduzir a reconstrução dos sentidos, embora as idéias transmitidas sejam sempre, mesmo que em um nível de menor criticidade, recontextualizadas e reconstruídas.

Conforme Chartier, as obras sempre estão investidas de diversas significações e têm mobilidade, sendo sempre dependentes do encontro do que é proposto pelo texto com a recepção de quem o acessa. "Os sentidos atribuídos às suas formas e aos seus motivos dependem das competências ou das expectativas dos diferentes públicos que delas se apropriam." (1994, p.9).

A conexão entre objetividade e subjetividade no processo de comunicação faz com que o conhecimento e a informação estejam dentro dos limites do contexto da produção e recepção. Porém, isso não implica o julgamento automático destes enquanto falsos ou verdadeiros, e sim a compreensão de que são objetos em constante construção que devem permitir o espaço crítico.

\section{CONCLUSÃO}

O ambiente de interação, necessário à formação e comunicação dos significados e dos sentidos, envolve a realidade sócio-histórica, as tecnologias de comunicação e informação disponíveis, bem como os sujeitos com suas possibilidades intra e intersubjetivas. Na verdade, a ação interacionista entre o homem e seu ambiente é estruturante do pensar humano, do próprio homem e de seu meio.

Como conseqüência dessa interação, o homem foi capacitando seu cérebro, desenvolvendo habilidades por meio das quais teve condições de gerar suas tecnologias e suas formas de vida em sociedade, tornando possível nesse processo sua capacitação para a formação de suas representações que dão visibilidade ao seu ser e estar no mundo. Através de suas representações, foi construindo os significados das coisas pertencentes ao mundo em que está inserido e, na vitalidade de sua interação com o meio, segue construindo e reconstruindo os sentidos em um processo dialético, no qual a educação desempenha papel fundamental e indispensável na construção da sociedade humana.

Cabe à sociedade, no interior das relações sociais, desenvolver olhar crítico sobre a formação dos sentidos e significados, buscando compreender as implicações do próprio uso das diversas tecnologias nesse processo e o papel predominante da comunidade científica e da indústria cultural enquanto geradores do conhecimento, considerando os ambientes informacionais e entendendo a educação formal enquanto co-autora, mediadora do acesso e promotora do ambiente do comentário. Um olhar crítico e vigilante aqui significa a proposta de um espaço que assegure a pluralidade, a multirreferencialidade, a multidimensionalidade, sem perder de vista a importância da interconectividade que permita o fortalecimento de sujeitos cada vez mais conscientes e capazes de viver uma dialogia, onde o comentário, a "contrapalavra", isto é, o espaço crítico, seja democraticamente garantido e respeitado.

\section{REFERÊNCIAS BIBLIOGRÁFICAS}

1. ALSTON, William P. Filosofia da linguagem. Tradução por Álvaro Cabral. Rio de Janeiro : Zahar, 1972. 161p. (Curso Moderno de Filosofia). Tradução de: Philosophy of language.

2. BARROS, Diana L. P. de. Contribuições de Bakhtin às teorias do discurso. In: BRAIT, Beth (Org.). Bakhtin, dialogismo e construção do sentido. Campinas : Editora da UNICAMP, 1997. 385p., parte 1: Bakhtin e as contribuições para a teoria da linguagem, p.27-38.

3. BECKER, Fernando. No princípio era a ação! Ação, função simbólica e inteligência emocional. Pátio : revista pedagógica, Porto Alegre, v.1, n.1, p.22-24, maio/jul. 1997.

4. BOUGNOUX, Daniel. Introdução às ciências da informação e da comunicação. Petrópolis : Vozes, 1994. 336p.

5. BURNHAM, Teresinha F. Complexidade, multirreferencialidade, subjetividade : três referências polêmicas para a compreensão do currículo escolar. Em Aberto, Brasília, v.12, n.58, p.3-13, abr./ jun. 1993.

6. CARDOSO, Ana Maria Pereira. Pós - modernidade e informação : conceitos complementares? Perspectivas em Ciência da Informação, Belo Horizonte, v.1, n.1, p.63-79, jan./jun. 1996.

7. CHARLE, Christophe, VERGER, Jacques. História das universidades. Tradução por Elcio Fernandes. São Paulo : Editora da UNESP, 1996. 131p. il. (Universitas). Tradução de: Histoire des universités. 


\section{Henriette Ferreira Gomes}

8. CHARTIER, Roger. A ordem dos livros : leitores, autores e bibliotecas na Europa entre os séculos XIV e XVIII. Tradução por Mary Del Priore. Brasília : Editora da UnB, 1994. 111p. il. Tradução de: L'ordre des livres : lecteurs, auteurs, bibliothèques en Europe entre XIVe et XVIIIe siècle.

9. DENNETT, Daniel. Linguagem e inteligência. In: KHALFA, Jean (Org.) A natureza da inteligência. Tradução por Luiz Paulo Rouanet. São Paulo : Editora UNESP, Cambridge University, 1996. 212p. il. Cap. 7, p.163-179.

10. DAVIS, Cláudia, OLIVEIRA, Zilma de. Psicologia na educação. 2. ed. rev. São Paulo : Cortez, 1994. 125p.

11. DENNY, J. P. O pensamento racional na cultura oral e a descontextualização da cultura escrita. In: OLSON, David R., TORRANCE, Nancy (Org.). Cultura escrita e oralidade. São Paulo: Ática, 1995. 286p. il. p. $75-99$.

12. FAGUNDES, Léa da C. A inteligência distribuída. Pátio : revista edagógica, Porto Alegre, v.1, n.1, p.15-17, maio/jul. 1997.

13. FERNANDES, Geni Chaves. O objeto de estudo da ciência da informação. INFORMARE : Caderno do Programa de PóGraduação em Ciência da Informação, Rio de Janeiro, v.1, n.1, p.25-30, jan./jun. 1995.

14. FOUCAULT, Michel. A arqueologia do saber. 4. ed. Rio de Janeiro : Forense Universitária, 1995. 239p.

15. FREIRE, Isa Maria. Informação; consciência possível; campo: um exercício com construtos teóricos. Ciência da Informação, Brasília, v.24, n.1, p.113-142, jan./abr. 1995.

16. GARDNER, Howard. Estruturas da mente : a teoria das inteligências múltiplas. Tradução por Sandra Costa. Porto Alegre: Artes Médicas, 1994. 340 p. il. Tradução de: Frames of mind : the theory of multiple intelligences.

17.

Pátio : revista pedagógica, Porto Alegre, v.1, n.1, p.34-37, maio/jul. 1997. Entrevista concedida diretamente de Cambridge (EUA).

18. GOMES, Henriette Ferreira. Compreendendo o universo tensivo na geração do sentido : uma tarefa da escola na construção do espaço crítico. Ágere : Revista de Educação e Cultura, Salvador, n.1, p. 23 - 36, jan./jun. 1999.

19. GONZÁlEZ DE GOMEZ, Maria Nélida. A representação do conhecimento e o conhecimento da representação : algumas questões epistemológicas. Ciência da Informação, Brasília, v.22, n.3, p.217-222, set./dez. 1993.

20. LÉVY, Pierre. As tecnologias da inteligência : o futuro do pensamento na era da informática. Rio de Janeiro : Ed. 34, 1993. 208p. il. (Coleção TRANS).

21. MARI, Hugo. Dos fundamentos da significação à produção do sentido. Perspectivas em Ciência da Informação, Belo Horizonte, v.1, n.1, p.93-109, jan./jun. 1996.

22. MARQUES, Mario Osorio. Escrever é preciso : princípio da pesquisa. Ijuí : Ed. UNIJUÍ, 1997. 162p.

23. MARTELETO, Regina Maria. Cultura da modernidade : discursos e práticas informacionais. Revista da Escola de Biblioteconomia da Universidade Federal de Minas Gerais, Belo Horizonte, v.23, n.2, p.115-137, jul./dez. 1994.

24.

Cultura, educação, distribuição social dos bens simbólicos e excedente informacional. INFORMARE : Cadernos do Programa de Pós-Graduação em Ciência da Informação, Rio de Janeiro, v.1, n.2, p.11-23, jul./dez. 1995a.
25.

Cultura informacional : construindo o objeto informação pelo emprego dos conceitos de imaginário, instituição e campo social. Ciência da Informação, Brasília, v.24, n.1, p.89-93, jan./abr. 1995b.

26. MORIN, Edgar. O método 4. : as idéias - habitat, vida, costumes, organização. Tradução por Juremir Machado da Silva. Porto Alegre: Sulina, 1998. 325p. Tradução de: La méthode 4. : les idées - leur habitat, leur vie, leurs moeurs, leur organisation, 1991.

27. NÖTH, Winfried. Panorama da semiótica : de Platão a Pierce. 2.ed. São Paulo : Annablume, 1998. 149p. (Coleção E, 3).

28. OlSON, David R., TORRANCE, Nancy (Org.). Cultura escrita e oralidade. São Paulo : Ática, 1995. 286p. il.

29. PACHECO, Leila Maria Serafim. A informação enquanto artefato. INFORMARE : Caderno do Programa de Pós-Graduação em Ciência da Informação, Rio de Janeiro, v.1, n.1, p.20-24, jan./jun. 1995.

30. PIERCE, Charles Sanders. Escritos coligidos. Seleção e tradução por Luís Henrique dos Santos. 4. ed. São Paulo : Nova Cultural, 1989. Conferência 6: Três tipos de raciocínio, p. 11 - 17.

31. PINTO, Julio. 1, 2, 3 da semiótica. Belo Horizonte : Editora da UFMG, 1995.69 p.

32. _____________emiótica e informação. Perspectivas em Ciência da Informação, Belo Horizonte, v.1, n.1, p.87-92, jan./jun. 1996.

33. POPPER, Karl R., ECCLES, John C. O eu e seu cérebro. Tradução por Sílvio M. Garcia, Helena C. F. Arantes e Aurélio C. de Oliveira. 2. ed. Brasília : UnB, Campinas : Papirus, 1995. 513 p. il. Tradução de: The self and its brain.

34. REGO, Teresa Cristina. Vygotsky : uma perspectiva histórico cultural da educação. 4.ed. Petrópolis : Vozes, 1997. 138p.

35. SARACEVIC, Tefko. Ciência da Informação : origem, evolução e relações. Perspectivas em Ciência da Informação, Belo Horizonte, v.1, n.1, p.41-62, jan./jun. 1996.

36. SFEZ, Lucien. Informação, saber e comunicação. INFORMARE : Cadernos do Programa de Pós-Graduação em Ciência da Informação, Rio de Janeiro, v.2, n.1, p. 5 -13, jan./jun. 1996.

37. SILVA FILHO, Waldomiro J. da. Compreensão e significação : redescrições hermenêuticas e semióticas. Salvador, 1995. 8p. Texto digitado.

38

Discursos da ação : primeiras notas para uma investigação sobre "enunciação" e "significação" no pragmatismo. In: O SENTIDO e a época. [Salvador : s.n., 1997]. p.163-184.

39. TEIXEIRA, Cláudia Hlebetz. Onde os intérpretes da informação? INFORMARE : Cadernos do Programa de Pós-Graduação em Ciência da Informação, Rio de Janeiro, v.1, n.2, p.37-44, jul./dez. 1995.

40. VYGOTSKY, L. S. Pensamento e linguagem. Tradução por Jeferson Luiz Camargo. São Paulo : Martins Fontes, 1995. 135p. il. Tradução de: Thought and language.

41. WERTSCH, James V. , SMOLKA, Ana Luiza B. Continuando o diálogo: Vygotsky, Bakhtin e Lotman. In: DANIELS, Harry (Org.). Vygotsky em foco : pressupostos e desdobramentos. São Paulo: Papirus, 1994. 296p. Cap. 4, p.121-149.

42. VALVERDE, Monclar Eduardo. Experiência e significação. In: $\mathrm{O}$ SENTIDO e a época. [Salvador : s.n., 1997]. p.185-195. 